\title{
IMPLICACÕES DO REUNI NO TRABALHO DOCENTE: PERCEPÇÃO DE PROFESSORES DOS CURSOS DE LICENCIATURA DA UNIVERSIDADE FEDERAL DO TRIÂNGULO MINEIRO (UFTM) ENTRE 2009 E 2016
}

\author{
IMPLICATIONS OF THE REUNI IN THE TEACHING WORK: PERCEPTION OF TEACHERS OF \\ THE TEACHING EDUCATION COURSES AT THE FEDERAL UNIVERSITY OF TRIANGULO \\ MINEIRO (UFTM) BETWEEN 2009 AND 2016
}

IMPLICACIONES DEL REUNI EN EL TRABAJO DOCENTE: PERCEPCIÓN DE PROFESORES DE LOS CURSOS LICENCIADORES DE LA UNIVERSIDADE FEDERAL DO TRIÂNGULO MINEIRO (UFTM) ENTRE 2009 Y 2016

\author{
Viviane Rocha Meirelles Guarato \\ E-mail: vivianermguarato@terra.com.br \\ Sálua Cecílio \\ E-mail: salua.cecilio@uniube.br \\ Universidade de Uberaba - UNIUBE
}

\begin{abstract}
RESUMO
O Programa de Apoio a Planos de Reestruturação e Expansão das Universidades Federais - REUNI, cuja finalidade primeira foi o aumento do número de vagas, matrículas e índices de conclusão de cursos de graduação presenciais entre outras, foi uma política pública de grande relevância para o Brasil. O objetivo deste artigo é divulgar uma pesquisa que teve como objetivo geral compreender as implicações do REUNI no trabalho docente, por meio da percepção de professores dos cursos de licenciatura da Universidade Federal do Triângulo Mineiro - UFTM de 2009 a 2016. A metodologia de abordagem qualitativa com informações discutidas pelo método da análise de conteúdo, teve como participantes professores das licenciaturas e compreendeu pesquisa bibliográfica e de campo - entrevista semiestruturada. Entre as principais implicações percebidas estão a intensificação do trabalho docente devido às atividades gestoras, alcance de metas de produções científicas, entre outras que se somam ao eixo principal integrado pelo ensino e a pesquisa contribuindo para uma evidente sobrecarga. Diante do exposto, inferese que as IFES necessitam planejar melhor as atividades dos professores, para não os sobrecarregar e afetar seu desempenho e realização profissional.
\end{abstract}

PALAVRAS-CHAVE: Expansão. Universidades Federais. Trabalho docente. REUNI.

\begin{abstract}
The Programa de Apoio a Planos de Reestruturação e Expansão das Universidades Federais - REUNI, whose primary purpose was to increase the number of vacancies, enrollments, and completion rates for on-site undergraduate courses, among others, was a public policy of great relevance for Brazil. This article aims to disseminate a research report that had as a general objective to understand the implications of REUNI in the teaching work, through the perception of professors of the undergraduate courses (teacher education programs) at the Federal University of Triângulo Mineiro - UFTM from 2009 to 2016. The qualitative approach methodology with information discussed by the content analysis method, it was attended by teachers from undergraduate courses and comprised bibliographic and field research - semi-structured interview. Among the main perceived implications are the intensification of teaching work due to management activities, the achievement of scientific
\end{abstract}


production goals, among others that add to the main axis integrated by teaching and research, contributing to an evident overload. Given the above, it appears that the IFES need to better plan the activities of teachers, so as not to overload them and affect their performance and professional achievement.

KEYWORDS: Expansion. Federal Universities. Teaching work. REUNI.

\section{RESUMEN}

El Programa de Apoio aos Planos de Reestruturação e Expansão das Universidades Federais - REUNI, cuyo propósito primordial fue aumentar el número de vacantes, matrículas y tasas de finalización de los cursos de pregrado presencial, entre otros, fue una política pública de gran relevancia para Brasil. Este artículo tiene como objetivo difundir un informe de investigación que tuvo como objetivo general comprender las implicaciones de REUNI en la labor docente, a través de la percepción de profesores de los cursos de pregrado (programas de formación docente) de la Universidad Federal del Triângulo Mineiro - UFTM desde 2009 al 2016. La metodología de enfoque cualitativo con información discutida por el método de análisis de contenido, contó con la participación de docentes de cursos de pregrado y comprendió investigación bibliográfica y de campo - entrevista semiestructurada. Entre las principales implicaciones percibidas se encuentran la intensificación de la labor docente por las actividades de gestión, el logro de metas de producción cientifica, entre otras que se suman al eje principal integrado por la docencia y la investigación, contribuyendo a una evidente sobrecarga. Dado lo anterior, parece que el IFES necesita planificar mejor las actividades de los docentes, para no sobrecargarlos y afectar su desempeño y logro profesional.

PALABRAS CLAVE: Expansión. Universidades Federales. Trabajo docente. REUNI.

\section{INTRODUÇÃO}

No âmbito das políticas educacionais e das reformas universitárias mais recentes, o ensino superior público - abordado historicamente como locus de propulsão tecnológica, bem como instrumento de formação crítica de conhecimentos e produção de saberes academicamente pesquisados e discutidos - busca um lugar estratégico no conjunto dos fenômenos e movimentos de transformação social, enquanto permite compreender o papel das universidades como instituições responsáveis pela produção, preservação e transmissão dos conhecimentos culturais, científicos e tecnológicos.

Este artigo originou-se da pesquisa de mestrado sobre as implicações do Programa de Apoio a Planos de Reestruturação e Expansão das Universidades Federais (REUNI), no trabalho docente, entre os anos 2009 e 2016, tomando como referência a percepção de professores dos cursos de licenciatura da Universidade Federal do Triângulo Mineiro (UFTM).

Na UFTM, aderir ao REUNI foi uma decisão administrativa, que contou com a participação do Conselho Administrativo e das Pró-reitorias, quando a maioria dos cursos em funcionamento foi expandida em outubro de 2009. Tal política, voltada exclusivamente para as universidades federais, traz como objetivo geral em seu artigo 1. .: "criar condições para a ampliação do acesso e permanência na educação superior, no nível de graduação, pelo melhor aproveitamento da estrutura física e dos recursos humanos existentes nas universidades federais". 
(BRASIL, 2007). O REUNI integra uma política de reestruturação articulada à democratização do acesso com inclusão social conforme prevê o Plano de Desenvolvimento da Educação (PDE).

Indubitavelmente, o REUNI pode ser considerado uma política pública com a missão de desenvolver e democratizar o ensino superior brasileiro, eliminando sua natureza elitista e mercantil. Por sua vez, quando vinculado ao PDE, o REUNI se transforma em uma proposta de política educacional; podendo ser classificado como um programa com objetivos múltiplos, a fim de se alcançar metas de qualidade no ensino em um período pontuado ou indefinido (LIMA, 2013).

A história da UFTM começa com a Faculdade de Medicina do Triângulo Mineiro (FMTM), uma faculdade isolada, com apenas o curso de graduação em medicina implantado em 1.954 e federalizada em 1.960. Muito tempo depois, foram implantados os cursos de enfermagem em 1.989 e biomedicina em 1.999. Com esses 03 (três) cursos, já era considerada uma instituição especializada na área da saúde e como tal pretendia ser reconhecida. No ano de 2.005, transforma-se em universidade, através de decreto do governo federal e passa a ser denominada Universidade Federal do Triângulo Mineiro (UFTM) com natureza jurídica de autarquia.

Em 2.006 são implantados os cursos de fisioterapia, nutrição, terapia ocupacional e licenciatura em letras português-inglês e português-espanhol. Conforme dados do Departamento de Registro e Controle Acadêmico da UFTM, a partir da implementação do REUNI, especialmente em 2.007, ampliaram-se as ofertas de vagas nos cursos de graduação e nos programas de pós-graduação já existentes, o que levou à expansão das pesquisas e eventos de extensão. Em 2.008 foi implantado o curso de psicologia. A partir da adesão ao REUNI, em 2.009, foram implantadas as licenciaturas, educação física e serviço social; em 2.010 as engenharias e em 2.012 a licenciatura em educação no campo e assim foi possível obter condições mais adequadas para o desenvolvimento de atividades de ensino, extensão e impulsionar a UFTM no campo da pesquisa.

De lá até a atual década, a instituição vem se consolidando cada vez mais como centro de formação e desenvolvimento profissional, expandindo-se em diversas áreas do conhecimento, chegando, em 2020, a um total de 25 cursos em Uberaba (biomedicina, ciências biológicas, educação física, enfermagem, engenharia ambiental, engenharia civil, engenharia de alimentos, engenharia de produção, engenharia elétrica, engenharia mecânica, engenharia química, física, fisioterapia, geografia, história, letras/português inglês, letras/português espanhol, matemática, medicina, nutrição, psicologia, química, serviço social, terapia ocupacional e licenciatura em educação do campo) e 03 no campus de Iturama (agronomia, biologia e química), além da oferta de vários programas em nível de pós-graduação lato sensu, programas de residência médica, cursos de especialização, pós-graduações stricto sensu, curso de aperfeiçoamento, cursos de extensão para a comunidade em geral, levando-se em consideração a alta demanda apresentada. Também ampliou suas atividades na área de saúde, quando então passaram a ser oferecidos, pelo Centro de Formação Especial em Saúde (CEFORES), cursos de educação profissionalizante voltados à formação de técnicos para atuar nos serviços de saúde. 
Dado tal contexto, este artigo discute as implicações do trabalho docente nos Cursos de Formação de Professores da UFTM, após a implantação do REUNI, entre os anos de 2009 e 2016. O objetivo é analisar as implicações do REUNI junto aos professores dos cursos de licenciatura e, por meio de suas percepções, os impactos em suas atividades docentes, sobretudo quanto à necessária promoção da qualidade-dedicação dos professores, apoio material, infraestrutura, entre outros aspectos e fatores - no processo de ensino universitário e a sua relação com a sobrecarga acarretada em virtude do aumento de vagas e número de matriculados nos cursos de licenciatura, no referido período.

\section{Pesquisa em educação no contexto da UFTM: métodos e recursos empíricos}

A UFTM contribui para mudanças nas realidades político-econômica, cultural e técnico-científica da região, do estado e do próprio país. Localizada no município de Uberaba-MG e fundada em 27 de abril de 1953, com um campus na cidade de Iturama-MG, a Universidade Federal do Triângulo Mineiro é uma instituição pública federal, que tem o importante papel de formar cidadãos científica e profissionalmente capacitados para se inserirem no mercado de trabalho e, ao mesmo tempo, atuarem com responsabilidade no meio social em que vivem.

Este artigo deriva-se de uma pesquisa de natureza qualitativa, cujos dados apoiaram-se em pesquisa bibliográfica, seguida da pesquisa de campo, por meio de entrevista, realizada com professores dos cursos de licenciatura da UFTM, durante os meses de junho e julho de 2017 . No período, foram entrevistados $14 \%$ dos docentes dos cursos de licenciaturas (16 participantes) de um total de 113 professores da área de formação de educadores. Definiu-se que seriam escolhidos dois professores de cada curso das licenciaturas, sendo eles os cursos: matemática, ciências biológicas, física, química, história, geografia, letras e ciclo comum. Os participantes foram selecionados dentre os professores que vivenciaram e trabalharam no período entre 2009 e 2016 e que se disponibilizaram em participar manifestando sua vontade.

À época, em 2017, segundo dados do Departamento de Registro e Controle Acadêmico, a expansão da Instituição cujo ápice foi o programa REUNI, contava com um contingente de mais de 7000 universitários, sendo mais de 5.800 nos cursos de graduação, 940 nos cursos de pós-graduação e 330 alunos da educação profissionalizante (CEFORES). Com relação aos cursos de licenciatura, o Instituto de Educação, Letras, Artes, Ciências Humanas e Sociais (IELACHS) da UFTM começou a atuar em agosto de 2010, com educadores dos cursos de licenciatura em geografia, história e letras (português-espanhol, português-inglês); cursos de bacharelado em psicologia, serviço social, professores do ciclo comum de formação e professores da área de educação, assim como servidores técnicoadministrativos e técnicos em assuntos educacionais. 

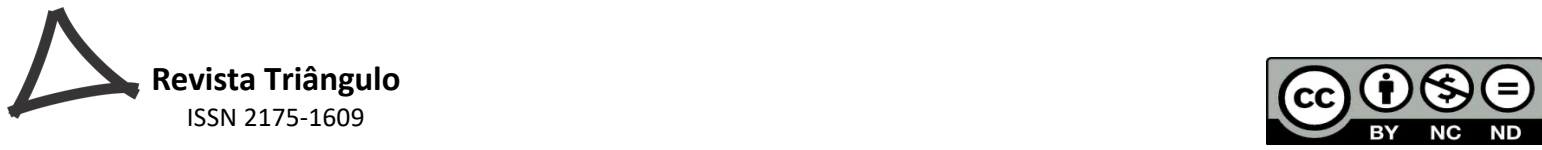

Para a realização da pesquisa, inicialmente foi solicitada autorização do Pró-Reitor de Ensino da referida Universidade, que a concedeu em maio de 2017. Após a autorização, os professores foram convidados a participar da pesquisa como entrevistados. Depois de esclarecidos sobre o seu teor e, consentindo em dela participar, todos os participantes assinaram o Termo de Consentimento Livre e Esclarecido.

A metodologia incluiu pesquisa bibliográfica e de campo. A pesquisa bibliográfica deuse a partir da consulta on-line às bases de dados da Biblioteca da Universidade de Uberaba, à Scientific Electronic Library Online - SciELO e ao Google Acadêmico, bem como às revistas impressas do acervo da Biblioteca Central da Universidade de Uberaba- Uniube. Na consulta, foram incluídos artigos e livros didáticos editados entre os anos de 2000 e 2015, todos em língua portuguesa e de autores brasileiros, com base nos seguintes descritores: história do ensino superior no Brasil, REUNI e reestruturação universitária, REUNI e a expansão universitária, impacto do REUNI no trabalho docente. Esses descritores foram lançados no campo de busca disponibilizado nos sites da Uniube, SciELO e Google Acadêmico.

Quanto à pesquisa empírica sobre a percepção do REUNI pelos convidados e selecionados para dela participar, recorreu-se ao uso de entrevistas semiestruturadas com 16 profissionais docentes dos cursos de licenciatura da UFTM (letras, história, geografia, física, matemática, química, ciências biológicas e ciclo comum), atuando na formação de professores. Durante a entrevista, buscou-se evidenciar a nova configuração da divisão do trabalho do professor, pós-REUNI, para que apontasse quais transformações mais afetaram o trabalho docente.

As informações obtidas por meio da entrevista foram analisadas pelo método da análise de conteúdo (BARDIN, 2011); quando então as unidades de registros foram categorizadas conforme a temática de cada núcleo da entrevista, sendo então agrupadas, para posterior análise e interpretações. No agrupamento, foram cruzadas as informações com estudos dos autores cujas ideias constituíram o referencial teórico.

Na análise de conteúdo, Bardin (2011) apresenta as seguintes etapas: a pré-análise, a exploração do material e o tratamento dos resultados (codificação e inferência). Com relação às técnicas de análise, essas abordaram a categorização e a interpretação do material coletado e selecionado a partir da pesquisa. Na perspectiva da análise do conteúdo, as informações foram categorizadas, primeiramente, apresentando-se o perfil dos professores e, em seguida, agrupando suas percepções e opiniões quanto à avaliação e gestão do tempo, às metas e à avaliação de desempenho. Na fase seguinte, ocupou-se em utilizar a inferência que, para Bardin (2011), trata-se de uma técnica de tratamento de resultados, necessária para comparar os enunciados, com a finalidade de constatar aproximações e distanciamentos entre as informações oferecidas pelos entrevistados e o que retratavam em relação ao pretendido.

Em seguida, durante a interpretação dos dados, retomou-se o referencial teórico, procurando fundamentar as análises, por meio de um diálogo com os autores pesquisados, indicando pesquisas que trazem dados semelhantes e também divergentes dos relatos dos 


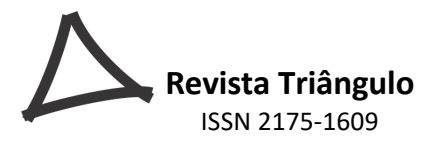

professores da UFTM, a fim de demonstrar que as implicações do REUNI no trabalho docente não ocorreram apenas na Universidade pesquisada, podendo atingir a todas as outras universidades que aderiram ao referido Programa, embora de forma diferenciada.

\section{A pesquisa em contexto: relatos e percepções de professores da UFTM}

No presente estudo, a percepção de professores dos cursos de licenciatura, quanto às implicações do REUNI no trabalho docente, em pesquisa realizada no interior da própria UFTM, revela um perfil de professores (todos com titulação de doutorado) que atuam com dedicação exclusiva de 40 horas destinadas ao ensino, à pesquisa e à extensão, podendo exercer cargos de gestão. Convém destacar que os professores integrantes da pesquisa são todos efetivos, aprovados em concurso público.

Durante a pesquisa de campo, em diálogo com os professores entrevistados, esses revelaram atividades que realizam fora da UFTM, sendo que as principais são a preparação de aulas, a elaboração e a correção de avaliações. Há também quem, a exemplo de um dos professores do curso de licenciatura em letras, lê e-mails institucionais, fora do ambiente de trabalho, e outros que leem materiais de pesquisa, artigos científicos e textos acadêmicos, didáticos e científicos, como ainda coordenam monitorias. Um dos docentes de química relatou que participa da Rede Mineira de Química e dos programas de pós-graduação dessa rede em parceria com a UFTM.

Além disso, um docente do curso de letras faz leitura de dissertações/teses para revisá-las, elabora relatórios, emite pareceres para revistas e agências de fomento em sua residência. Há professores entrevistados que realizam atividades virtuais permanentes, orientando os alunos fora do campus da UFTM, inclusive escrevem artigos que são exigidos como meta dentre outras, como por exemplo: a participação em eventos científicos, em bancas de defesa de mestrado/ doutorado, além da elaboração e submissão de projetos a órgãos de fomento.

Ainda quanto às atividades realizadas fora da UFTM, chama a atenção o seguinte relato, que salienta atividades realizadas em sua residência:

Realizo a preparação das reuniões e do trabalho em extensão, porque, na extensão, a gente busca a informação no arquivo, cataloga de alguma forma essa informação e precisa ser tabulada. Essa tabulação é feita fora, em casa, muitas vezes utilizando equipamento pessoal, esse tipo de coisa, e tem a preparação da aula, que é inevitável (Prof. 14). 

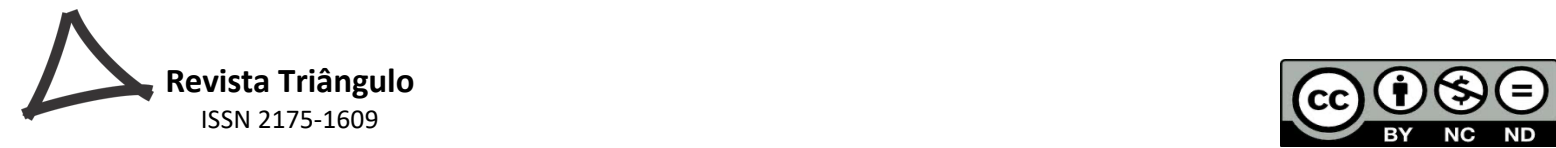

Ora de modo diferenciado, ora de modo comum ao dos demais, em uma tendência cada vez mais forte na profissão, as atividades profissionais se misturam à vida pessoal, acarretando consequências diversas para os professores e à sua vida familiar. Como muitos outros, os professores têm levado atividades da UFTM para serem realizadas em casa, quando, na realidade, deveriam utilizar esse tempo no convívio e relacionamento com suas famílias e/ou qualquer outra atividade que não seja relacionada ao trabalho. Isso porque, ao assumir a docência na UFTM, sua carga horária é de 40 horas de dedicação exclusiva à Universidade, sendo admitido, e mesmo passível de avaliação, como inoportuno e problemático, o fato de realizar atividades em sua própria residência.

Durante as entrevistas, os docentes reportaram desempenhar algumas atividades que não estão relacionadas à docência como coordenação e gestão, editoração de periódicos, pesquisas em outros cursos da Universidade entre outras. Estas atividades, apesar de serem realizadas dentro das 40 horas de dedicação exclusiva, sobrecarregam a atividade docente, mesmo que previstas cada vez mais como inerentes ao trabalho de professores, principalmente aos que também atuam na pós-graduação. Desse modo, a atuação do professor torna-se extensa, pois precisa coadunar processo educativo e ações administrativas e outras que não se limitam às atividades de ensino em sala de aula.

Há também docentes que realizam atividades de pesquisa e extensão fora da UFTM, em outras instituições de ensino superior e educação básica. Entre outras, há o desenvolvimento de projetos de extensão em escolas públicas de educação básica; atividades em escolas parceiras da UFTM, realizadas fora dos campi; atividades nas ruas centrais da cidade e bairros de Uberaba, junto a pessoas que circulam nos espaços públicos e trabalhadores informais; contato com escolas para desenvolvimento de projetos extensionistas; coordenação de pesquisas junto ao Arquivo Público de Uberaba. Nessa direção, a pesquisa revelou, ainda, que alguns professores têm tarefas integrantes do seu rol de atividades, que são realizadas em outras instituições de ensino, mostrando que a sobrecarga pode advir de atividades nem sempre relativas às parcerias com outras instituições, uma vez que não mencionaram serem tais atividades realizadas em instituições parceiras da UFTM. Desse modo, quando não há parceria e eles se ocupam em executar tarefas, para além da dedicação exclusiva, isso pode se configurar como extensão de jornada e influenciar na qualidade de sua atuação docente.

Com relação à gestão do tempo para execução de todas as suas atividades em 40 horas semanais, os relatos apontaram que mais da metade deles têm uma sobrecarga de trabalho devido à escassez de professores nos cursos de licenciatura, para atender às demandas didático-pedagógicas (preparação de aulas e de instrumentos de avaliação, correção de atividades avaliativas, leitura e escolha de textos a serem discutidos em sala de aula, entre outras), conforme apontado pelo professor 1. 


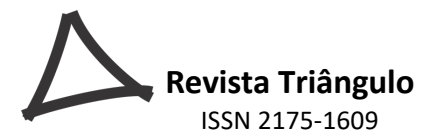

Há uma sobrecarga, porque faltam professores para atender às demandas de disciplinas pedagógicas dos cursos de licenciatura. Com isso, o tempo fica restrito para corrigir tantos trabalhos dos discentes, além do desgaste na realização com turmas muito cheias, o que acarreta prejuízo das atividades diárias. Em 2014, tivemos uma professora do nosso departamento com 82 alunos em sala de aula! (Prof. 1).

Obviamente, que o trabalho do professor não se resume apenas às atividades de ensino conhecidas como ministrar aulas, dado que a docência compreende também a preparação, elaboração de instrumentos de avaliação, sua aplicação e correção, além de outras funções relacionadas à pesquisa e extensão. Cabe salientar que as turmas com numerosos alunos levam ao desgaste do professor, uma vez que ele precisa dar atenção a um volume maior de dificuldades e particularidades dos universitários. Daí, a necessidade de atenção a situações e aspectos como o tamanho da turma - a exemplo da que conta com 82 alunos, que requer dos gestores e coordenadores de curso maiores cuidados técnicos e pedagógicos, para não se comprometer a qualidade do ensino e da aprendizagem.

Ainda com relação ao tempo, os relatos apontam que as atividades de cargos administrativos gerenciados pelos professores tornam o tempo escasso. Além disso, o tempo é também insuficiente diante do acúmulo de atividades como o PIBID, orientações de TCC, grupos de discussão, participação em comissões e em reuniões de professores. Grande parte dos professores entrevistados salienta que o tempo é escasso e os docentes encontram-se sobrecarregados. A prof ${ }^{a}$. 14 afirma que há maior tempo gasto com atividades administrativas do que com a docência, sendo que o ensino ganha menos dedicação que a necessária.

No relato do professor de história (Prof. 15), sobre a administração do tempo, podese destacar:

\footnotetext{
Diante da demanda, principalmente como professor que exerce cargo de coordenação de curso, acaba que o tempo é bem curto, na minha opinião. Tendo em vista que há uma enorme gama de e-mails que recebemos, além disso tem que fazer a leitura desses e-mails, recebimento de documentação, enviar documentação, ou seja, memorandos para os demais setores da Universidade solicitando aulas, solicitando disciplinas, vagas para disciplinas para o próximo semestre, entre outras questões. Então o tempo, eu considero bastante corrido dentro da Universidade.
}

Não apenas para a docência, a pesquisa e a extensão é direcionado o tempo dos professores; existem aqueles que a tais atividades se somam cargos de chefia e de coordenação, o que aumenta a demanda do tempo gasto por eles. A emissão de pareceres e a elaboração de relatórios, o envio e a recepção de documentos podem restringir o tempo a ser dedicado ao ensino, pois as atividades destinadas à aprendizagem devem ser as mais importantes para assegurar a qualidade do processo educativo. 


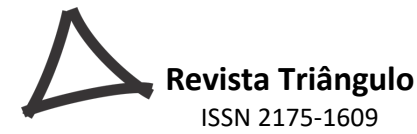

Nesse sentido, uma das professoras entrevistadas (área de disciplinas pedagógicas Prof ${ }^{a}$. 1) relata que: "A intensificação do trabalho, a pressão para aumento da produtividade e adoecimento são realidades que hoje permeiam a vida do professor universitário. Eu mesma fui diagnosticada com síndrome do burnout ${ }^{1}$ e fiquei 6 meses afastada para tratamento". Tal relato reforça a necessidade de se refletir sobre a relação entre atribuições docentes e condições para seu exercício; de modo a resguardar a qualidade do trabalho e da formação de alunos que promove. Isso remete à importância de se avaliarem metas e prioridades que favoreçam aos gestores da UFTM e docentes a definição de prioridades que orientem o redimensionamento do seu trabalho, de modo a promover o seu exercício saudável e conforme exigências institucionais, porém observados quesitos e ambientes favoráveis à saúde individual e coletiva, evitando o desgaste funcional em função do tempo insuficiente para desenvolver atribuições funcionais e/ou seu acúmulo que pode relacionarse a ou acarretar doenças laborais.

Corroborando análises sobre o adoecimento do professor e a sobrecarga do trabalho, tem-se o comentário de docente da pós-graduação:

\begin{abstract}
Alguns colegas enxergam que o REUNI condena a gente a uma vida de professor de graduação. A gente indo para a pós-graduação acaba sendo uma penalização do professor, pois tem uma carga horária muito grande e um número de alunos muito grande em sala de aula. Então a grande maioria dos professores ou não vai para a pós-graduação ou se vai, é à custa de muito sacrifício. Justamente pela sobrecarga que a gente tem e pelo número pequeno de docentes. Então essa situação gera um impacto de adoecimento dos professores, a gente vê todo mundo com muita coisa para fazer, fazendo tudo com muita dificuldade, muita correria, muita sobrecarga, muito estresse, então é isso que vejo (Prof. 4).
\end{abstract}

Evidentemente, quando o número de alunos ultrapassa o ideal para cada professor, há um aumento da sua responsabilidade que pode levá-lo ao estresse e à síndrome de burnout. Esse quadro que pode gerar o adoecimento é uma dentre as várias consequências de políticas externas e posturas relacionadas às políticas internas da instituição a serem repensadas e debatidas com seus segmentos, de modo a estabelecer uma política de prevenção de doenças e atenção à saúde com medidas que possam contribuir para diminuir a sobrecarga de trabalho, melhorar a administração do tempo e assegurar a saúde e a qualidade de vida do professor no seu ambiente de trabalho.

Comprova-se, por meio desta pesquisa, que além da docência, pesquisa e extensão, os professores também estão sobrecarregados com atividades de gestão, coordenação, participação em comissões, conselhos, comitês, colegiados, reuniões e outras, o que lhes "toma muito tempo", conforme relato do Prof. 4. O fato de haver professores que se deslocam das atividades de ensino para as de gestão e de coordenação de cursos evidencia a intensificação do trabalho docente, requerendo estudos e busca de alternativas no interior da UFTM que propiciem um maior equilíbrio entre atividades de ensino, de gestão, de 
pesquisa e extensão. Para alguns, a indicação de um docente para a gestão de curso, sem utilizá-lo em outras atividades que não fossem ligadas a essa, evitaria ou minimizaria riscos de excessiva sobrecarga funcional. Seria uma forma de buscar esse equilíbrio desejado pela instituição para o bem-estar e a saúde do docente. Mas, para que isso aconteça, são necessários outros estudos para avaliar como é possível estabelecer formas de equilíbrio entre as dimensões do trabalho docente de modo que a qualidade dele seja viável e coerente com o esperado e previsto para o conjunto da instituição, observadas suas finalidades essenciais. Além disso, para muitos segmentos e setores da sociedade, há de se buscar e alcançar uma mudança no padrão das atuais políticas públicas relacionadas à educação.

Do mesmo modo, há quem defenda que a UFTM teria que deliberar sobre o assunto, buscando uma decisão em que todos os docentes que exercessem cargos de administração/coordenação não executariam, durante sua gestão, atividades de ensino, pesquisa e extensão. Uma boa medida ainda seria que os docentes que detivessem cargos de gestão passassem a coordenar e a desenvolver os eventos referentes ao seu curso, a exemplo do PIBID, PET, assim como comemorações, solenidades, cerimônias, reuniões de professores, entre outras. Porém, a exemplo de algumas posições favoráveis à dedicação exclusiva ou prioritária a uma ou outra atividade seja de gestão, ensino ou de extensão, para evitar sobrecarga de trabalho, há análises que avaliam haver um prejuízo na formação e atuação docente cuja atuação não integre gestão, ensino e pesquisa ou extensão. De todo modo, evidencia-se que as considerações, expectativas e demandas postas pelos participantes requerem investigações e debates sobre implicações diversas que daí poderão advir, seja para eles mesmos, seja para os alunos, para a comunidade e/ou para o conjunto da instituição.

Com relação às metas estipuladas e às agendas de ensino, pesquisa e extensão que são atribuídas, pelos setores internos, aos professores, houve uma pluralidade de opiniões diante dos relatos dos entrevistados, pois essas metas exigem a intensificação do trabalho do professor, evidenciada pela alta produtividade de artigos científicos, grande volume de participação em eventos científicos, elaboração de projetos de graduação e pós-graduação, orientações de alunos de iniciação científica, entre outras. Embora se reconheça a importância do alcance dessas metas, enquanto permitem a avaliação de desempenho e influenciam na progressão da carreira do professor universitário, o que ocorre tem sido objeto de muitas discussões e polêmicas quanto ao fato de se prestar a avaliar mais a quantidade da produção do que propriamente a qualidade dessa produção que os docentes realizam. Em relação às metas, a minoria dos professores entrevistados as considera equilibradas no que diz respeito ao seu cumprimento.

No referente à exigência de cumprir metas de produtividade, a Prof. ${ }^{\text {a }} 2$ de licenciatura em letras acredita que não houve grandes impactos, porque os docentes já produziam muito antes do REUNI. Porém, há educadores entrevistados que justificam a sua falta de atenção às atividades docentes e aos alunos, pela necessidade de cumprir metas nem sempre exequíveis. Diante tal relato, cabe considerar que as metas deveriam ser adequadas à carga horária de ensino, pesquisa e extensão, para que o professor tivesse tempo suficiente para desenvolvê-las adequadamente, 


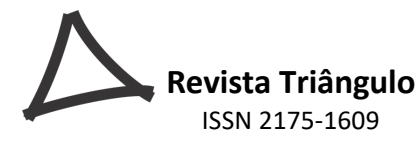

com benefícios ao processo ensino-aprendizagem, que deveria ser a primeira meta a ser perseguida/alcançada.

Houve professores entrevistados que levantaram críticas em relação às metas estabelecidas para os cursos de licenciatura, entre os quais se pode destacar o relato do docente 16:

\begin{abstract}
As metas em si não são ambiciosas, inexequíveis, sobre o ponto de vista da proposta de meta, de olhar: temos de produzir! O grande problema é você encontrar amparo material para fazer isso. E isso não tem. Vou tomar por base o curso de história. O curso de história é um curso importante na Universidade, tem formado bons profissionais, tem um bom diálogo com a cidade e tem muita dificuldade, por exemplo, de ter um laboratório de estágio, de ter um laboratório audiovisual que, para nós, é condição fundamental. (Prof. 16).
\end{abstract}

Evidentemente, para se cumprirem metas preestabelecidas, necessita-se de apoio e de infraestrutura, sobretudo quanto aos espaços pedagógicos diversificados e materiais didáticos disponíveis e de fácil acesso. Nesse sentido, fica evidente que às metas se articulam condições para que sejam viabilizadas e alcançadas, conforme previsto em um planejamento institucional devidamente compartilhado e acompanhado. Pelo exposto, é possível admitir que há quem considere necessário que a UFTM necessita, conforme relato acima, rever as metas para que sejam exequíveis. Isso porque, se a Universidade não possui uma estrutura material, cumprir a meta se torna complexo, exigindo do professor maior criatividade e, ao mesmo tempo, maior empenho e dedicação de tempo.

Importante apreciar a questão da produtividade em relação às metas, como ficou evidenciado pelo professor entrevistado:

\footnotetext{
Veja, veja bem, para você pleitear, até um certo tempo atrás, bolsa de iniciação científica, para você ter duas bolsas, você tinha que ter, no mínimo, dez artigos publicados nos últimos cinco anos. Pelo menos isso era o que era exigido em alguns editais de iniciação científica. Ora, para um professor, da área de humanas, do curso de licenciaturas, diante de uma grande quantidade de atividades docentes a serem desempenhadas, como você vai escrever, ter dez artigos nos últimos cinco anos, uma média de dois artigos por ano, levando em consideração que o critério de avaliação das revistas é bastante demorado, principalmente para professores que não fazem parte de seu quadro de programa de pós-graduação, é muito complicado (Prof. 15).
}

Embora a UFTM possua revistas próprias, para publicação de artigos de alunos e professores da graduação e pós-graduação, segundo o relato do professor entrevistado, encaminhar artigos a outras revistas de seu interesse é recomendável, buscando divulgar sua produção em veículos externos à Instituição em que atua. Aqui ele depara com algumas 


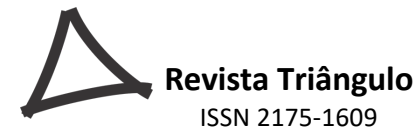

dificuldades, seja em função dos critérios adotados pela revista, seja pelo tempo requerido para avaliação dos artigos submetidos, o que, em última análise, compromete o tempo disponibilizado para a média de publicações periódicas.

Ainda em relação ao impacto das metas sobre os professores, podem-se ter distorções de finalidades e inversão de valores. Ou seja, o que poderia ser uma estratégia para estimular a pesquisa e a socialização do conhecimento fica reduzido a um recurso de quantificação de produção docente e pode resultar em mero instrumento de medida e de classificação de docentes em produtivos e não produtivos ou pouco produtivos, sem atentar ao que a isso subjaz. Afinal, não se trata de negar a importância de metas, mas de considerá-las separadas de uma política institucional clara de planejamento e de condições para que os resultados esperados sejam possíveis e sirvam ao alcance de objetivos voltados principalmente ao ensino, à pesquisa e à extensão.

Ainda sobre as metas da UFTM, para os professores, após o REUNI, o Prof. 16 relata:

Então, às vezes, o docente deixa mesmo de se envolver em várias outras questões que a universidade pede e exige para se dedicar a publicar e manter sua vida acadêmica em dia e tudo mais. Tem outros, que é meu caso, que não conseguiram conciliar essas duas dimensões com o mesmo grau de excelência. Uma vez que você se dedica mais a construir o curso, construir regulamento e tal, você acaba deixando um pouco de lado essa coisa de manter a meta da produção científica.

Nesse caso, a convergência entre o tempo e a intensificação das atividades dos docentes pode prejudicar o cumprimento das metas, sobretudo para aqueles que atuam na área administrativa, em reuniões de colegiado, comissões e comitês. Do mesmo modo, ao procurar cumprir as prioridades de cada curso, a produtividade pode ficar comprometida, pois o fator tempo é essencial para produção de artigos científicos e outras metas propostas pela UFTM.

Indubitavelmente, não há como ignorar a necessidade de metas que orientem e explicitem quantidade e tempo para o cumprimento de objetivos e, por isso, podem estar vinculadas à produtividade, mas vê-se que elas necessitam ser planejadas com representatividade de docentes de todos os cursos de licenciatura, para que haja possibilidade de cumpri-las, além de permitir que tragam satisfação pessoal e profissional aos professores. Sendo assim, é forçoso ressaltar que, sem uma articulação com as políticas institucionais de planejamento e acompanhamento, podem-se gerar subprodutos na cultura organizacional - como insatisfação e pouco envolvimento na vida institucional, além de produzir o contrário do esperado: ao invés do cumprimento de tais metas, gerar descrença, frustração e isolamento impactando negativamente o desempenho e a avaliação de desempenho do professor.

No que se refere a este quesito, a avaliação de desempenho do professor universitário foi a temática mais polêmica e a que gerou relatos muito interessantes. Os professores entrevistados das licenciaturas da UFTM vincularam a avaliação à produtividade, ao tempo 


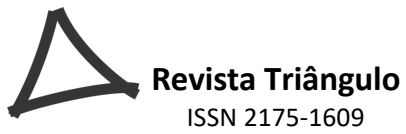

e às metas. Há professores que acreditam ser a avaliação de desempenho adequada, mas a Profa. 2 afirma que a avaliação deveria ser mais rígida e impactar na progressão da carreira. Além disso, argumenta que os professores universitários se têm formado em serviço e que tal fato prejudica o ensino.

Outros entrevistados disseram que, na avaliação, considera-se a possibilidade de o educador justificar suas horas de trabalho em várias atividades, prevendo que o professor possa registrar a atividade que realmente executa em sala de aula. Nesse sentido, a avaliação é ampla, com a finalidade de considerar as várias funções que o docente realiza. Por outro lado, existem aqueles que relataram que a avaliação é parcialmente pertinente, uma vez que não contempla todas as atividades exercidas como o trabalho em rede (virtual), que é primordial para o desenvolvimento da Universidade.

Contudo, diferentemente dessa visão, entre os entrevistados, há quem considere ser a avaliação adequada, justificando que agrega valores e benefícios na formação profissional, mas não enumerou tais benefícios e valores. Também há quem não soube opinar, alegando não saber a qual avaliação de desempenho a pesquisa se referia.

Relatos do Prof. 3 reportam que os critérios adotados pela Comissão Permanente de Pessoal Docente (CPPD), na avaliação funcional, exigem muita dedicação do docente ao ensino, à pesquisa e à extensão, mas o educador discorda do peso maior que recai sobre a quantidade de publicação em detrimento de outras atividades também relevantes, como orientações a pesquisas de iniciação científica e ao TCC. O exposto sinaliza uma compreensão do alcance e pertinência da avaliação no contexto da construção e progressão na carreira, acompanhada pela CPPD.

Portanto, não se trata de negar a importância e a necessidade da avaliação, mas de defender critérios e condições para que cumpra sua função essencial, conforme sinalizam os relatos dos professores 14 e 16 .

Considero a avaliação docente, realizada pelo aluno muito importante e que precisa ter seu papel, critérios, objetivos, funções, forma de realização, formas de sistematização e análise, permanentemente repensadas, debatidas, reorganizadas por toda a comunidade escolar. Infelizmente, acredito que isso não tem sido uma realidade na maioria das universidades brasileiras (Prof. 14).

Acho que essa pergunta tem que ser respondida pelos meninos. É difícil a gente fazer essa avaliação. Eles gostam do curso. Se identificam muito. Quem está no curso tem um profundo sentimento de identidade com o curso, o que não significa de aceitação de tudo, que não tem um modo de percepção crítica, dos limites, virtudes, potencialidades, defeitos que certamente tem e tem que ter. Porque é obra humana (Prof. 16). 


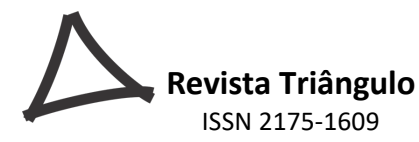

Segundo essa visão avaliativa, a escuta sobre a avaliação dos alunos, quanto ao trabalho docente é importante, pois são os interlocutores em sala de aula, portanto aptos a avaliarem o processo educativo e sugerir novas abordagens e dinâmicas pedagógicas. Desse modo, é pertinente escutar atentamente os alunos e perceber sua expressividade quanto ao trabalho do professor que está diretamente envolvido com os discentes no cotidiano de suas aulas.

Além disso, a realização profisssional do professor universitário e a relação universidade-sociedade são igualmente importantes. Realmente, a formação ética do aluno é de suma importância na sua formação universitária e deveria permear o processo avaliativo do professor do ensino superior. A valorização do professor, com efeito, supõe uma postura social, mais respeitosa e de reconhecimento do seu trabalho, pois o respeito pelo trabalho docente é de grande relevância para que a avaliação funcional agregue valores na realização pessoal do professor.

Uma visão mais ampla do processo avaliativo dos professores é considerada como tendo impacto no curso de licenciatura de modo geral, ou seja, quando o professor percebe que sua atuação tem agregado valores aos alunos. Nesse quesito, a avaliação é realmente falha se não há a avaliação do docente por parte dos alunos, que são os protagonistas do ensino superior.

Ainda no relacionado à realização profissional e pessoal do professor, o relato do professor 14 realça o lugar da avaliação do aluno como importante recurso para o aperfeiçoamento de melhoria do ensino.

É por meio destas avaliações que o professor consegue ter melhores condições de se autoavaliar, procurar sanar problemas e melhorar sua prática de ensino. São formas de o professor identificar questões e dimensão das práticas que realiza; que, por vezes, ele não pode se dar conta do que tem alcançado com elas ou não, durante anos sem a avaliação pelo sujeito que integra sua atividade, o aluno (Prof. 14).

De fato, a autoavaliação e a reflexão sobre a própria prática pedagógica são momentos em que a avaliação funcional deveria abrir a oportunidade para o educador melhor se conhecer e se posicionar em relação ao seu trabalho e às condições em que é exercido. Desse modo, quando o aluno avalia o ensino com base na sua aprendizagem, juntos, professor e aluno podem melhorar a qualidade do processo educativo universitário, conforme sugerido pelo Professor 1.

\footnotetext{
Não acho que a Avaliação de Desempenho traga benefícios, nem qualidade ao ensino. Seria pertinente se houvesse melhores condições de trabalho, se não se colocasse a responsabilidade exclusiva no professor pelas mazelas do ensino brasileiro, se houvesse mais confiança no trabalho docente e menor pressão para aumentar a produtividade a partir da consideração de que uma produção de qualidade não condiz com produtividade massificada e quantitativa como é exigida. (Prof. 1).
} 

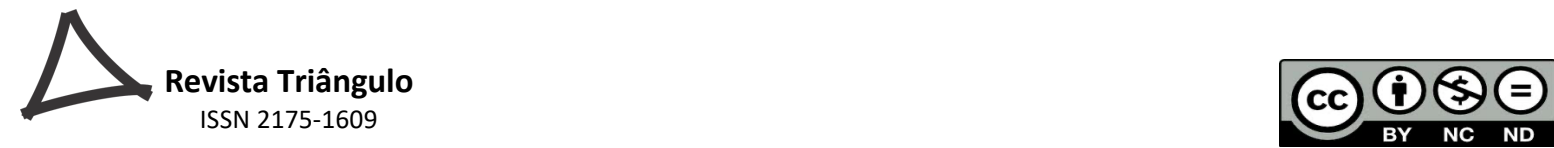

No âmbito do REUNI, a ampliação de vagas e matrículas sem a contrapartida da instituição de ampliar também o número de docentes e servidores técnico-administrativos para auxiliá-los nas secretarias de cursos, acarretou dificuldades de se atingir metas na proporção e qualidade desejáveis. Uma das políticas que têm chamando a atenção de muitos e causado incomodo e queixas, às vezes generalizadas, é a relacionada à publicação obrigatória de artigos visando a produtividade, tendo critério meramente quantitativo e que, não condiz com uma postura avaliativa mais ampla e coerente com as mudanças que se quer alcançar com o programa de expansão e reestruturação. Desse modo, as condições de trabalho devem ser avaliadas em conjunto com a avaliação funcional do professor.

A análise e as críticas sobre a relação entre o trabalho docente e a avaliação de desempenho são de grande importância, pois permitem esclarecer alguns dos impactos do programa de reestruturação e expansão nas atividades do professor sobre o ensino e seus resultados. No conjunto e para uma avaliação dos efeitos e implicações do REUNI, podese admitir que a valorização da docência é um dos principais requisitos para que a avaliação agregue valores à prática educativa. No entanto, precisa ser processual e formativa, dado ocorrer diariamente no cotidiano de suas atividades de ensino, pesquisa, extensão e gestão e para tais atividades deve-se voltar, de modo a melhorá-las e não só para diagnosticá-las.

Sendo processual, implica ser contínua e dinâmica. Afinal, o trabalho docente e a prática pedagógica podem e devem ser avaliados junto aos alunos, acatando sugestões, para recriar e inovar, tendo como respaldo a avaliação dos discentes. Processual porque não se atém a um único momento - avaliação anual de desempenho - mas se amplia em um espectro de dimensões variadas (postura, comportamento, atitudes, diversidade de temáticas tratadas, tecnologias utilizadas, expressividade, argumentatividade), motivando os alunos a serem pesquisadores e construtores permanentes de uma nova concepção de educação superior e valorizar ainda mais a docência.

\section{Diálogos entre os domínios empíricos e teóricos}

No cenário atual das instituições de ensino superior brasileiras, incluindo a Universidade Federal do Triângulo Mineiro (UFTM), o REUNI destaca-se como um projeto político educacional que permitiu às IFES assumirem e cumprirem sua função junto à sociedade brasileira com a formação de profissionais comprometidos com a construção de uma sociedade justa, democrática, solidária e pluralista. Plural como é o trabalho docente e suas percepções sobre as mudanças que ocorreram nos cursos de licenciatura entre os anos de 2009-2016 na UFTM.

Com efeito, a pluralidade das percepções e opiniões dos professores enriquece a pesquisa, uma vez que traz diferentes perspectivas sobre a realidade do trabalho docente quando da implantação do REUNI. Essa visão plural e, ao mesmo tempo, singular, 


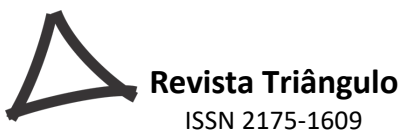

compreende um conjunto de argumentos críticos, essencial para se visualizar diferentes posturas quanto ao ensino, pesquisa, extensão, gestão do tempo e avaliação funcional. $\mathrm{Na}$ singularidade, ou seja, na expressividade particular de cada professor, tem-se a sua própria visão autoral do trabalho docente, o que tem grande relevância para demonstrar a diversidade de pontos de vista dentre os vários docentes de uma mesma instituição de ensino superior.

Mancebo; Vale; Martins (2015) esclarecem que o REUNI veio com o propósito de não apenas aumentar o número de estudantes de graduação nas universidades federais e o número de estudantes por professor em cada sala de aula da graduação (dezoito alunos de graduação por professor em cursos presenciais), mas também para diversificar as modalidades dos cursos de graduação, por meio da flexibilização dos currículos, da instituição da Educação a Distância (EaD), da criação dos cursos de curta duração, dos ciclos (básico e profissional) e/ou bacharelados interdisciplinares; tendo em vista incentivar a criação de um novo sistema de títulos; elevar a taxa de conclusão dos cursos de graduação para $90 \%$ e estimular a mobilidade estudantil entre as instituições de ensino (públicas e/ou privadas).

Ao se cruzarem os dados coletados, observou-se que todos os professores entrevistados lecionam em cursos de sua área de formação inicial. Entretanto, oito professores atuam em cursos que não são da área de sua graduação, inclusive dois professores em outro curso que não é licenciatura (serviço social). Há três professores que exercem a docência em cursos de mestrado e pós-graduação lato sensu.

Estudos que revelam esse deslocamento do professor para outras áreas de atuação na docência encontram-se, entre outros, em Brandão; Ferenc; Braúna (2015, p. 343):

Nesse sentido, o que se pode analisar, a partir dessas questões, é que cada
vez mais o trabalho do professor das universidades, públicas
especialmente, tem se expandido para além de seu campo pedagógico, e
esse profissional, por sua vez, vem vivenciando a intensificação de seu
trabalho. As mudanças trazidas pelas reformas educacionais mais recentes
têm resultado em ampliação do seu raio de ação e, consequentemente, em
maioria de desgastes e insatisfação por parte desses trabalhadores.

Nessa citação se faz possível reconhecer a convergência com os relatos dos entrevistados, que indicam deslocamentos para atividades gestoras, para além de seu campo de ação pedagógica, pois em não havendo professores suficientes para assumirem as disciplinas de um dado curso, como ocorre na UFTM, a lógica é utilizar os professores de outras graduações para preencher essas lacunas. Mesmo que o professor tenha competências e conhecimentos para assumir turmas em outros cursos que não os de sua formação inicial, isso poderia ser uma postura provisória, pois o desejável e esperado é que a Universidade busque e consiga alocar docentes para lecionar em seu campo de ação, mesmo que seja por contratação temporária. 


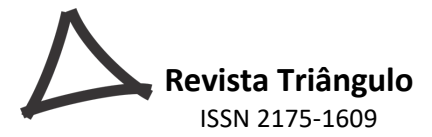

Considerando os relatos dos professores entrevistados, constata-se que o trabalho docente é significativo e prioritário no desenvolvimento institucional, podendo ter, no REUNI, um feedback para desenvolver e garantir melhores resultados na qualidade da produção dos professores e pesquisadores na UFTM. Da mesma forma, ao investir na gestão do tempo e na qualidade da atuação do educador, promove-se a dimensão cultural e científica das IFES, rumo a uma nova construção da identidade docente universitária em cada instituição que aderiu ao REUNI, sendo que a UFTM tem grande potencial para pesquisa e divulgação científica.

Com relação ao tempo, os professores entrevistados apontaram que existe uma sobrecarga pelo número insuficiente de professores nos cursos de licenciatura, para acolher as demandas didático-pedagógicas.

Em uma pesquisa sobre a expansão, via REUNI, Pachane e Vitorino (2015, p. 453) afirmam que: "A precarização do trabalho docente, pelo aumento da sobrecarga de trabalho, é ampliada pelo fato de haver poucos docentes no novo modelo de gestão". Na UFTM, devido ao REUNI, ocorreu a escassez de professores, pois houve poucos concursos públicos para docentes das licenciaturas, fazendo com que os professores se desdobrassem para alcançar as metas e administrar o tempo destinado ao ensino, realizando, na maioria das vezes, em tempo extra ao da jornada de trabalho.

É importante ressaltar que as turmas com numerosos alunos levam ao desgaste do professor, porquanto dele se espera atenção a um volume maior de dificuldades e particularidades de cada universitário, o que demanda tempo para dedicar às diferenças no cotidiano das aulas, conforme relatos dos professores das licenciaturas da UFTM participantes dessa pesquisa.

Além disso, os relatos dos entrevistados apontam que as atividades de cargos administrativos exercidos pelos docentes na UFTM tornam o tempo escasso. Há, para alguns professores, maior tempo gasto com atividades administrativas do que com o ensino, sendo que a preparação das aulas ganha menos dedicação que o necessário. Tal quadro confirma haver uma tendência ao aumento do trabalho polivalente e multifuncional no ensino superior. Conforme Batista (2013, p. 26): “a polivalência se expressa por múltiplas atividades (...) e administração. Esse último aspecto tem sido cada vez mais exigido dos docentes que sofrem com os procedimentos e processos decisórios". Nesse sentido, se o professor fica restrito à gestão/coordenação, sem ministrar aulas, pode sobrecarregar outros professores, que deverão assumir suas turmas. Assim, mostra-se inevitável na UFTM, que o professor, ao mesmo tempo, administre, coordene e atue no ensino, intensificando seu trabalho. Isso porque, os processos decisórios em nível de gestão e/ou coordenação demandam a elaboração de pareceres e a confecção de relatórios, decisões ágeis e eficientes como despachar documentos em tempo hábil, ser motivador para professores e alunos por meio de uma atitude proativa, estimuladora, participar como líder e ser articulador em reuniões, funções acadêmicas, resolver problemas de gestão, supervisão de instalações físicas, laboratórios e equipamentos, além das solicitações de materiais para suprir as 

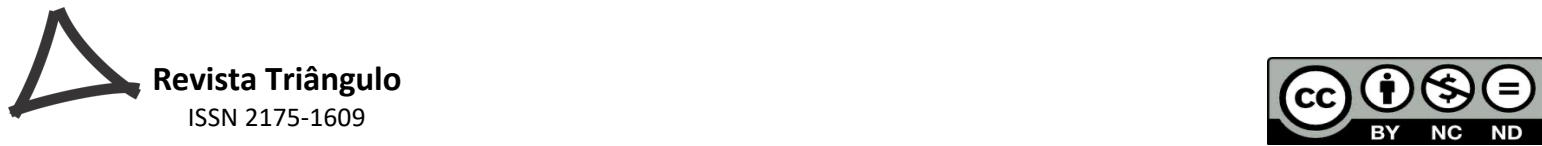

atividades cotidianas, aumentando, ainda mais, a sobrecarga do trabalho docente e, até mesmo causando o adoecimento do professor.

Dada tal conjuntura, os resultados sinalizam a necessidade de a UFTM encontrar alternativas para planejamento de ações que favoreçam rever o volume de atividades administrativas junto aos professores, pois quando o tempo é insuficiente para executá-lo e as condições pessoais e institucionais são restritas ou se mostram aquém do minimamente necessário, abre-se um quadro favorável ao aparecimento de insatisfações e desequilíbrios na relação trabalho e saúde, podendo culminar na ocorrência de doenças relacionadas ao trabalho. Essa implicação no trabalho docente é uma das questões que requer da UFTM como um todo, um conjunto de ações para avaliar e rever suas agendas e prioridades de gestão, de modo a evitar o adoecimento em função da sobrecarga de trabalho e do tempo escasso disponível, dado que o docente afastado por motivo de saúde agrava ainda mais a falta de professores.

No cruzamento entre o tempo, as metas e a intensificação das atividades dos docentes, a exigência da produção acadêmica pode prejudicar não apenas o cumprimento de metas, mas também pode impactar a avaliação funcional dos professores. Do mesmo modo, ao buscar cumprir as prioridades de cada curso, quanto à qualidade do ensino superior, a produtividade pode ficar comprometida, pois o fator tempo é essencial para a qualidade dos artigos produzidos e a participação em eventos científicos deveria ser uma escolha do professor.

Vale destacar que as metas não são apenas as aplicadas individualmente a cada professor; há aquelas instituídas pelo Plano Nacional de Educação (PNE) que, de acordo com Souza (2014, p. 29),

[...] dependem, indiscutivelmente, da atuação efetiva das instituições [de ensino superior]. [Assim], nada mais justo do que a participação de recursos federais destinados ao financiamento da expansão de suas atividades, evitando que estas sejam relegadas ao descumprimento dos seus princípios de autonomia.

No que se refere às metas instituídas após o REUNI na UFTM, o quadro de intensificação torna-se mais evidente e também polêmico, se considerados os relatos de alguns entrevistados, pois conforme relato de uma professora entrevistada que acha que não houve grandes impactos, porque os docentes da UFTM já produziam muito, mas por outro lado, atesta que há alguns docentes que justificam a sua falta de atenção às atividades docentes e aos alunos porque há a necessidade de se cumprirem as metas e que essas nem sempre são alcançadas, como a produção de artigos e a participação em eventos científicos. Outro entrevistado diz que nem sempre a Universidade disponibilizou infraestrutura e apoio financeiro para aquisição de materiais para pesquisa dificultando o alcance das metas propostas. De acordo com o relato de outra professora entrevistada que disse que a 


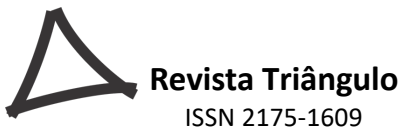

intensificação do trabalho, a pressão para aumento da produtividade e o adoecimento são realidades que hoje permeiam a vida do professor universitário. Outra opinião atesta que, com a implantação do REUNI, não se tem tempo suficiente, pois além de produções acadêmicas, publicação de artigos, ainda tem que se desdobrar com as questões administrativas; faltando estrutura e boas condições de trabalho para os professores, o que dificulta atingir as metas estipuladas. Um professor considera as metas de produção científica bastante equilibradas, embora haja docentes que até as desconheçam.

Entre as implicações do REUNI no trabalho docente, a avaliação de desempenho do professor universitário para progressão funcional, aliada à produtividade, foi o aspecto mais controverso, pois, ao lado de uma minoria afirmando ser adequada, encontra-se a maioria que critica os critérios adotados, havendo até mesmo os que defenderam que poderia ser mais rigorosa. Do mesmo modo, alguns professores acreditam que, durante a avaliação funcional, eles poderiam justificar a escassez de tempo para executar suas horas de trabalho, razão pela qual não alcançaram a produtividade almejada. Importante ressaltar que os parâmetros da avaliação funcional, na UFTM, contemplam todas as funções que o docente realiza, incluindo as administrativas.

Nessa linha de raciocínio, de acordo com Souza (2014); Dal Ri; Floro (2015), a avaliação funcional de professores universitários, pelo critério da produtividade, tem se constituído em uma maneira de exigir dos docentes o cumprimento de metas e agendas de ensino, pesquisa e extensão. Nessa visão, que não é diferente da que ocorre na UFTM, busca-se um controle maior do trabalho docente, restringindo as oportunidades de valorização qualitativa do trabalho docente que possam agregar valores de satisfação profissional.

Para a grande maioria dos professores entrevistados, a avaliação de desempenho nos moldes em que foi instituída não é apropriada, não agrega valores, nem benefícios na formação profissional. Entretanto, alguns dos critérios adotados pela CPPD da UFTM para progressão/promoção na carreira do magistério superior são:

a) a participação de atividades de ensino como aulas teóricas ou práticas em cursos regulares da UFTM, em cursos de pós-graduação lato sensu ou stricto sensu, elaboração de projetos de ensino a estágios supervisionados, TCC, orientação e coorientação a tese de doutorado, supervisão de pós-doutorado, orientação e coorientação a dissertação de mestrado, orientação a monografia de pós-graduação lato-sensu; b) produção intelectual como produção de artigo técnico-científico, publicação de artigos em periódicos, publicação de trabalho completo e resumo em anais de reunião científica internacional e nacional, publicação de livros, resenhas, capítulo de livro, ser membro de comissão julgadora de eventos, ser presidente de conselho editorial de revista, membro, diretor geral ou editor responsável de revista científica, revisor de revista científica, membro de banca de mestrado, membro de banca de doutorado, participação em entrevistas, mesas redondas; c) participação de atividades de pesquisa como coordenar projetos de pesquisa, ser membro de equipe de projeto de pesquisa, apresentar trabalhos em reunião científica nacional e internacional, proferir palestras, conferências, ministrar 


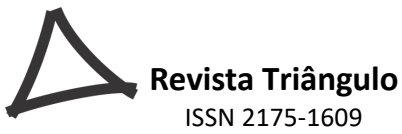

minicurso, participar de debates em eventos científicos; d) participar de atividades de extensão como coordenar projetos, programas, ligas acadêmicas cadastradas na instituição, coordenar programas como PIBID, PROEXT, Prodocência, PETS; e) participar de atividades administrativas, gestão, como ser coordenador, diretor, chefe de setores e serviços como: Central de Idiomas, Centro Cultural, Centro de Educação a Distância, ser membro (titular ou suplente) de comissão e/ou comitê temporário da UFTM, ser reitor, vice-reitor, pró-reitor, coordenador de curso de graduação, coordenador de curso de pós-graduação; f) participar de atividades representativas e sindicais como ser dirigente ou membro da diretoria da Associação dos Docentes da UFTM, ser presidente ou vice-presidente, em efetivo exercício, da diretoria de associação relacionada à sua área profissional; g) e participar de outras atividades como ser orientador de monitoria de disciplinas de graduação, participar em bancas de concurso público e processo seletivo de professor (BRASIL, 2014).

Essas são algumas das atividades de ensino, pesquisa, extensão e gestão para promoção na carreira de professor de magistério superior do plano de carreiras e cargos de magistério federal da UFTM, que busca valorizar devidamente o magistério do ensino superior, mesmo havendo um peso maior em relação à produtividade, sobretudo quanto à publicação de artigos e participação em eventos científicos, conforme o encontrado nas entrevistas semiestruturadas feitas com os professores da UFTM e o exposto na Lei 12.772 (e alterações) (BRASIL, 2012) que rege a progressão funcional dos servidores pertencentes ao Plano de Carreiras e Cargos de Magistério Superior da UFTM juntamente com o anexo I da Resolução $\mathrm{n}^{0}$ 13, de 26 de junho de 2014, do Conselho Universitário da UFTM.(BRASIL, 2014). Nesse sentido, pode-se deduzir que a atuação da CPPD guarda coerência com aspectos da literatura e com legislação federal.

Semelhante a essa linha de pensamento, a pesquisa de Silva $(2008$, p. 46) aponta que: "A avaliação assenta-se num modelo que cria uma espiral produtiva, relacionada ao alcance de metas cada vez mais ambicioso, o que induz à frenética superação de indicadores para a progressão à carreira". A avaliação está atrelada à produtividade e cumprimento de metas. Porém, importa que sejam adotados critérios de autoavaliação e reuniões/escuta dos alunos para maior valorização da docência, fazendo com que a progressão funcional não seja refém de critérios quantitativos de avaliação. Da conjugação de avaliações internas e de revisão de políticas públicas e legislações federais, poderão surgir mudanças de critérios, formas e métricas de avaliação, conforme sinalizam algumas tendências de avaliação que vêm sendo adotadas nos últimos anos e em algumas instâncias do ensino federal.

De fato, há uma outra visão por parte dos entrevistados desta pesquisa que converge para a realização profissional do docente universitário e a relação educação-sociedade, para os quais, a opinião dos alunos nos processos de avaliação é igualmente importante. Com efeito, a valorização da docência pelo discente é oportuna e deveria permear o processo avaliativo do professor do ensino superior. A valorização do professor, realmente, precisa ser amplamente fundamentada na avaliação dos discentes, pois estes são importantes protagonistas da educação universitária. 

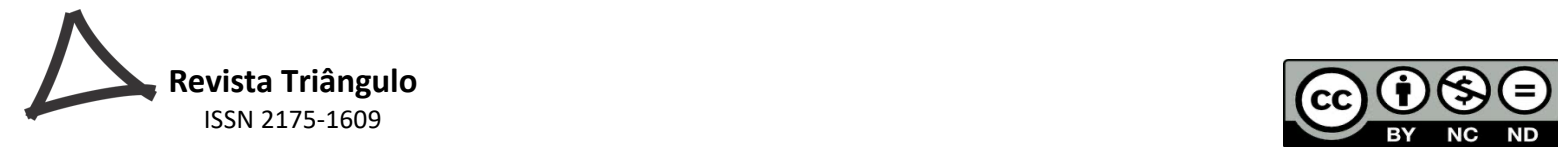

Essa visão mais ampliada do processo educativo como um todo, não apenas vinculada à produtividade, é vista como ideal pelos professores das licenciaturas da UFTM, pois o professor, em sala de aula, percebe que sua atuação tem agregado valores aos alunos. Nesse parâmetro, a avaliação restrita aos índices de produtividade pode apresentar distorções e gerar uma prática produtivista, mostrando-se ser realmente falha, se os alunos não participarem do processo avaliativo dos professores, porque o trabalho docente destinase, primeiramente, aos acadêmicos universitários.

No entanto, a avaliação funcional, segundo os participantes desta pesquisa, é uma mera rotina que tem por finalidade a progressão na carreira docente, na qual o educador deve realizar suas atividades restritas à produtividade. Todavia, para haver mudanças no processo de avaliação docente, os instrumentos de avaliação funcional precisam ser reestruturados e oportunizar mais o diálogo e valorizar os critérios qualitativos, a fim de se buscar soluções para a qualidade do processo ensino-aprendizagem.

Mesmo que o trabalho tenha intensificado, sobrecarregando o docente e o submetido a uma avaliação funcional com critérios restritivos e pautada na progressão da carreira do professor, no âmbito das instituições federais de ensino superior, o REUNI trouxe a oportunidade a mais alunos de ingressarem no ensino superior. Se se pensar que a ampliação das vagas e matrículas foi benéfica à população brasileira que busca o ensino para ampliar seus conhecimentos e se formar em uma profissão em nível superior, de fato, é uma política pertinente na contemporaneidade.

Por isso mesmo, em sua reestruturação e expansão, embora tenha se voltado para a produtividade, o REUNI foi uma das mais relevantes políticas educacionais no Brasil, mesmo com metas que possam não ser totalmente e sempre exequíveis. Nesse sentido, cabe aos professores lutarem por condições de trabalho docente que mudem esta realidade, pois a política de reestruturação e expansão das IFES foi uma abertura ao acesso e à permanência do aluno no ensino superior, sendo um fato relevante na história da educação superior brasileira.

\section{CONSIDERAÇÕES FINAIS}

A partir do estudo realizado junto aos professores de licenciaturas da Universidade Federal do Triângulo Mineiro, pode-se argumentar que a expansão do ensino superior trouxe para as instituições federais de ensino superior, dentre outras consequências, o aumento de vagas e matrículas, que pode afetar a qualidade do trabalho docente. Isso porque o professor pode ficar sobrecarregado e, a partir daí, ter impactados o preparo de aulas, a escolha de materiais para debate em sala de aula, a promoção de pesquisas junto aos discentes, entre outas atividades igualmente importantes como a criação de instrumentos de avaliação. 

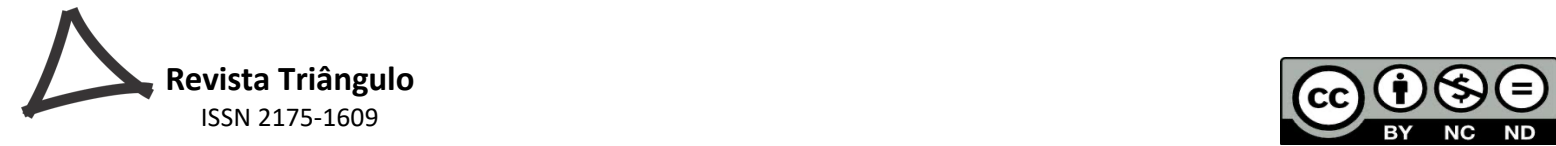

Por meio da presente pesquisa, foi possível dar visibilidade às atribuições dos docentes de licenciatura da UFTM, incluindo atividades para além do ensino, pesquisa e extensão, que exigem muito de seu tempo, obrigando-os a realizarem tarefas em sua residência. Afinal, a frequência com que se leva trabalho para casa e o seu volume precisam ser repensados e modificados, para que o professor que já detém 40 horas de dedicação exclusiva para executar as suas atividades, não precise estender ainda mais a sua jornada para o seu lar, tendência cada vez mais comum no mundo do trabalho docente do século 21. Para muitos não se justifica trabalhar na residência, num período em que o docente deveria se dedicar mais à sua vida familiar e pessoal.

Do mesmo modo, quanto ao tempo destinado ao trabalho docente, os dados da pesquisa demonstram que o trabalho dos professores foi intensificado, gerando sobrecarga $\mathrm{e}$ até mesmo adoecimento. Um planejamento coletivo e flexível - reunindo professores, coordenadores de curso e diretores das unidades de ensino em uma visão que possibilite revisar as diretrizes planejadas sempre que houver mudanças significativas em seu desenvolvimento - poderia sanar ou minimizar os efeitos do problema da intensificação do trabalho docente, momento em que a UFTM dialogaria com os docentes a partir de uma escuta crítica, procurando superar a sobrecarga resultante de um grande contingente de alunos, com aumento concomitante das atribuições dos professores de licenciatura.

Nessa linha de pensamento, as metas e a avaliação funcional resultaram em mudanças na rotina do professor, pois o foco está na produtividade, quando deveria recair na qualidade do processo ensino-aprendizagem. Desse modo, uma nova visão e revisão das metas, fundamentadas em um processo qualitativo de produção acadêmica pode ser pensada, tanto pelas universidades como pelas agências de fomento e pela própria CAPES, no sentido de buscarem soluções conjuntas após ouvirem os professores universitários.

\section{REFERÊNCIAS}

BARDIN, Laurence. Análise de Conteúdo. São Paulo: Edições 70, 2011.

BATISTA, Ana Carolina P. B. Condições de trabalho docente na universidade frente ao Programa de Apoio a Planos de Reestruturação e Expansão das Universidades Federais (REUNI). 2013. 95f. Dissertação (Mestrado em Educação). Universidade Federal de Viçosa: UFV, 2013.

BRANDÃO, Ana Carolina P.; FERENC, Alvanize V. F.; BRAÚNA, Rita. C. A. Condições de trabalho docente na universidade pública brasileira: um mapeamento de estudos. Espaço Pedagógico, v. 22, n. 2, p. 343-355, 2015.

BRASIL. Lei $\mathbf{n}^{\mathbf{0}} \mathbf{1 2 . 7 7 2}$, de 28 de dezembro de 2012. Dispõe sobre a estruturação do Plano de Carreiras e Cargos de Magistério Federal; sobre a Carreira do Magistério Superior, de que trata a Lei $\mathrm{n}^{\circ}$ 7.596, de 10 de abril de 1987; sobre o Plano de Carreira e 

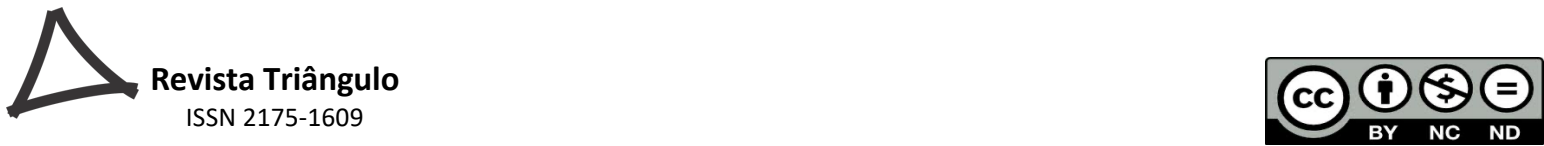

Cargos de Magistério do Ensino Básico, Técnico e Tecnológico e sobre o Plano de Carreiras de Magistério do Ensino Básico Federal, de que trata a Lei n ${ }^{\circ} 11.784$, de 22 de setembro de 2008...etc. Disponível em: http://www.planalto.gov.br/ccivil 03/ ato20112014/2012/lei/112772.htm.

BRASIL. Decreto no 6.096 de 24 de abril de 2007. Institui o Programa de Apoio a Planos de Reestruturação e Expansão das Universidades Federais - REUNI. Brasília, 2007. Disponível em: http://www.planalto.gov.br/ccivil_03/_ato2007-

2010/2007/decreto/d6096.htm.

BRASIL. Expansão das universidades federais. Brasília: Ministério da Educação Portal Brasil, 2016. Disponível em:

http://portal.mec.gov.br/index.php?option=com_docman\&view=download\& alias=12386analise-expansao-universidade-federais-pdf\&Itemid=30192.

BRASIL. Ministério da Educação. Universidade Federal do Triângulo Mineiro.

Resolução n. 13, de 26 de junho de 2014, do Conselho Universitário da UFTM. Dispõe sobre a progressão funcional e promoção dos servidores pertencentes ao Plano de Carreiras e Cargos de Magistério Superior da UFTM, de que trata a Lei 12.772, de 28 de dezembro de 2012 (e alterações). Disponível em: https://docplayer.com.br/16995847Resolucao-n-13-de-26-de-junho-de-2014-do-conselho-universitario-da-uftm.html.

BRASIL. REUNI 2008 - Relatório do primeiro ano. Brasília: MEC/SESU, 2009. Disponível em:

http://portal.mec.gov.br/index.php?option=com docman\&view=download\&alias=2069reuni-relatorio-pdf\&category slug=dezembro-2009-pdf\&Itemid=30192.

DAL RI, Neusa Maria; FLORO, Elisângela F. Trabalho docente e avaliação de desempenho. Interfaces da Educação, v. 6, n. 16, p. 66-89, 2015.

LIMA, Paulo G. Políticas de educação superior no Brasil na primeira década do século XXI: alguns cenários e leituras. Avaliação, v. 18, n. 1, p. 85-105, 2013.

MANCEBO, Deise; VALE, Andréia A.; MARTINS, Tânia Barbosa. Políticas de expansão da educação superior no Brasil 1995-2010. Revista Brasileira de Educação, v. 20, n. 60, p. 31-50, 2015.

PACHANE, Graziela G.; VITORINO, Bruna M. A expansão do ensino superior no Brasil pelo programa REUNI: democratização da formação universitária ou apenas uma ambivalência legal? Poiésis, v. 9, n. 16, p. 438 - 456, 2015.

SILVA, Maria das Graças Martins da. Trabalho docente na pós-graduação: a lógica da produtividade em questão. 2008. Orientadora: Maria Estela Dal Pai Franco. 204 f. Tese (Doutorado em Educação) - Programa de Pós-graduação em Educação. Universidade Federal do Rio Grande do Sul, Porto Alegre - RS, 2008. Disponível em: https://lume.ufrgs.br/handle/10183/15514.

SOUZA, Moacir A. Impactos da política de expansão da educação superior instituída a partir do governo Lula sobre as condições do trabalho docente na UEPB. 2014. 66 p. Trabalho de Conclusão de Curso (Graduação em Administração). Universidade Estadual da Paraíba, Campina Grande, 2014. Disponível em: 
http://dspace.bc.uepb.edu.br/jspui/bitstream/123456789/8641/1/PDF \%20\%20Moaci\%20Arnaldo\%20de\%20Souza.pdf.

\footnotetext{
${ }^{1}$ Esta síndrome pode ser definida como uma resposta ao estresse laboral crônico característico do trabalho que tenha contato com pessoas. Estes profissionais apresentam deterioração cognitiva (perda da motivação e baixa realização no trabalho) e afetiva (esgotamento emocional e físico com desgaste psíquico), e, em consequência a estes sintomas, passam a desenvolver condutas negativas frente aos clientes e à instituição (indiferença, frieza e distanciamento). Referência: BARBOSA, Andrea L. K. H. Síndrome de burnout em professores universitários. Maringá: Unicesumar, 2016.
} 